\title{
The Patient Research Partner Network Matures: A Report from the GRAPPA 2017 Annual Meeting
}

\author{
Niti Goel, Denis O’Sullivan, Maarten de Wit, Chris A. Lindsay, Heidi Bertheussen, John Latella, \\ Jeffrey Chau, Roland MacDonald, Suzanne Grieb, Ingrid Steinkoenig, and Willemina Campbell
}

\begin{abstract}
The Group for Research and Assessment of Psoriasis and Psoriatic Arthritis (GRAPPA) has reached the third of 5 stages of organizational maturity regarding incorporating patient research partners (PRP) into psoriatic arthritis (PsA) and psoriasis research and educational efforts. Herein, we report the involvement of PRP at the GRAPPA 2017 annual meeting and plans for future PRP engagement. (J Rheumatol Suppl. 2018 June;94:52-3; doi:10.3899/jrheum.180138)
\end{abstract}

Key Indexing Terms: PSORIATIC ARTHRITIS GRAPPA

\section{PATIENT RESEARCH PARTNERS PATIENT CENTRICITY PSORIASIS ORGANIZATIONAL MATURITY}

Over the last 5 years, the Group for Research and Assessment of Psoriasis and Psoriatic Arthritis (GRAPPA) has made substantial progress to incorporate patient input into the group's work. As a result, the GRAPPA patient research partner (PRP) network has evolved in parallel. Herein, the PRP network's involvement since the GRAPPA 2016 annual meeting and their evolution as a group since their first formal attendance at the GRAPPA 2013 annual meeting are summarized.

From the Advisory Services, IQVIA, Adjunct Assistant Professor, Duke University School of Medicine, Durham, North Carolina; International Dermatology Outcome Measurers, Windsor, Connecticut; Johns Hopkins University School of Medicine, Center for Child and Community Health Research, Baltimore, Maryland; Cleveland Clinic, Cleveland, Ohio, USA; Our Lady's Hospice and Care Services, Dublin, Ireland; Department of Medical Humanities, VU University Medical Centre, Amsterdam, the Netherlands; Biomedical Laboratory Scientist, Oslo University Hospital, Oslo, Norway; Hong Kong Psoriatic Arthritis Association, Hong Kong, China; Toronto Western Hospital, Psoriatic Arthritis Clinic, Toronto, Ontario, Canada.

As part of the supplement series GRAPPA 2017, this report was reviewed internally and approved by the Guest Editors for integrity, accuracy, and consistency with scientific and ethical standards.

N. Goel, MD, Patient Research Partner, Vice President, Advisory Services, IQVIA, Adjunct Assistant Professor, Duke University School of Medicine; D. O'Sullivan, BE, Patient Research Partner, Our Lady's Hospice and Care Services; M. de Wit, PhD, Patient Research Partner, Department of Medical Humanities, VU University Medical Centre; C.A. Lindsay, PharmD, Patient Research Partner; H. Bertheussen, Cand.mag, Patient Research Partner, Biomedical Laboratory Scientist, Oslo University Hospital; J. Latella, BS, MS, Patient Research Partner, and Board Member, International Dermatology Outcome Measurers; J. Chau, BA, MCS, Patient Research Partner, Hong Kong Psoriatic Arthritis Association; R. MacDonald, Patient Research Partner, Toronto Western Hospital, Psoriatic Arthritis Clinic; S. Grieb, PhD, MSPH, Patient Research Partner, Johns Hopkins University School of Medicine, Center for Child and Community Health Research; I. Steinkoenig, BA, Patient Research Partner, Cleveland Clinic; W. Campbell, BEd LLB, Patient Research Partner, Toronto Western Hospital, Psoriatic Arthritis Clinic. Address correspondence to Dr. N. Goel, IQVIA, 5827 S. Miami Blvd., Morrisville, North Carolina 27560,USA.E-mail:niti.goel@iqvia.com
PRP Involvement at the GRAPPA 2017 Annual Meeting Premeeting. Twelve PRP who attended the GRAPPA 2017 annual meeting were educated on the Core Outcome Measures for Psoriatic Arthritis Clinical Trials (COMPACT) study. They then participated in focus groups to evaluate the content validity and feasibility of selected patient-reported outcome measurements. The summary of this premeeting is planned to be presented separately. Generally, such collaboration between patients and researchers should improve researcher understanding of the effect of psoriatic arthritis (PsA) on patients and patient priorities regarding outcomes. Subsequently, the PRP, including 1 who attended by Skype, and the PRP Executive Liaison met to evaluate an initial draft of the PRP Policies and Procedures document.

During the GRAPPA 2017 meeting, PRP were present at all sessions. They participated in breakout groups that built upon the premeeting work to evaluate instrument content validity and feasibility. During the GRAPPA project update session, PRP shared how their membership has progressed (Table 1). From 2013 through 2017, 16 PRP had attended at least 1 meeting, and 3 PRP had consecutively attended all 5 annual meetings since 2013 .

\section{PRP Involvement in GRAPPA Activities}

Since the GRAPPA 2016 annual meeting, PRP have continued to be involved in multiple projects, including several activities related to the Outcome Measures in Rheumatology-GRAPPA update of the PsA core set, the COMPACT study, the composite measures consensus meeting, the PsA treatment guidelines slide deck, the GRAPPA mobile device application, the GRAPPA research proposals review, and the GRAPPA Collaborative Research Network. In addition, PRP are planning how best to disseminate the PRP-generated booklet, A Patient's Guide to Treatments for Psoriatic Arthritis.

Reflecting upon the PRP premeeting work, PRP shared

Personal non-commercial use only. The Journal of Rheumatology Copyright $@$ 2018. All rights reserved 
Table 1. Evolution of PRP attendance at annual GRAPPA meetings from 2013 to 2017.

\begin{tabular}{|c|c|c|c|c|c|}
\hline Characteristic & 2013 & 2014 & 2015 & 2016 & 2017 \\
\hline Males, n (\%) & $3(43)$ & $4(50)$ & $4(50)$ & $5(45)$ & $6(50)$ \\
\hline Asian & $1(14)$ & $1(13)$ & $1(13)$ & $2(18)$ & $2(17)$ \\
\hline White & $6(86)$ & $7(87)$ & $7(87)$ & $8(73)$ & $9(75)$ \\
\hline Latin American & - & - & - & $1(9)$ & $1(8)$ \\
\hline Europe & $4(50)$ & $3(38)$ & $3(38)$ & $3(27)$ & $4(33)$ \\
\hline North America & $4(50)$ & $5(62)$ & $5(62)$ & $6(55)$ & $6(50)$ \\
\hline South America & - & - & - & $1(9)$ & $1(8)$ \\
\hline
\end{tabular}

PRP: patient research partners; GRAPPA: Group for Research and Assessment of Psoriasis and Psoriatic Arthritis.

with the general GRAPPA membership that the PRP network is creating a governance document to dovetail with the current GRAPPA bylaws, and that they plan to create a PRP handbook to provide additional details. Further, the GRAPPA Executive Committee assigned an Executive Liaison to facilitate the PRP network.

These latter activities highlight how the GRAPPA PRP network may be operating close to the third level of organizational maturity, the "Defined" maturity level, in the Capability Maturity Model Integration (CMMI) model (Table $2)^{1,2}$. This model, originally used to define best practices related to software development, has been expanded to help organizations improve their processes at all levels from services to people.

The GRAPPA PRP network has not undergone any formal process improvement procedures and may not be the type of organization intended to undergo a CMMI assessment. However, as the PRP network continues to develop, achieving a state similar to those described in levels 4 and 5 of the CMMI model might signal that PRP themselves start to lead the investigation of their own questions related to psoriatic disease as considered at the GRAPPA 2016 annual meeting ${ }^{3}$.
PRP are actively defining their participation within the GRAPPA community. As their role evolves within the organization, the benefits realized from their contributions to GRAPPA initiatives will hopefully be recognized and grow. The PRP appreciate their involvement in GRAPPA and anticipate a future where incorporating patient input into research and educational endeavors is routine.

\section{ACKNOWLEDGMENT}

We thank Rodrigo Firmino, PhD, Professor, Pontifical Catholic University of Parana, Curitiba, Brazil, for his participation in this patient research partners effort.

\section{REFERENCES}

1. What is Capability Maturity Model Integration (CMMI)? [Internet. Accessed February 14, 2018.] Available from: cmmiinstitute.com/capability-maturity-model-integration

2. CMMI Product. CMMI for Service, Version 1.3, CMMI-SVC V.1.3 CMU/SEI-2010-TR034, Technical Report, Software Engineering Institute, 2010.

3. Goel N, O’Sullivan D, Steinkoenig I, James J, Lindsay CA, Coates LC, et al. Tackling patient centricity: a report from the GRAPPA 2016 Annual Meeting. J Rheumatol 2017;44:703-5.

Table 2. Capability Maturity Model Integration organization maturity levels.

\begin{tabular}{ll}
\hline Level & Description \\
\hline 1: Initial & Processes unpredictable, poorly controlled, and reactive \\
2: Managed & $\begin{array}{l}\text { Processes characterized for projects and often reactive } \\
\text { 3: Defined }\end{array}$ \\
$\begin{array}{l}\text { Processes characterized for the organization and proactive (projects tailor } \\
\text { their processes from organization's standards) }\end{array}$ \\
5: Optimizing & $\begin{array}{l}\text { Processes measured and controlled } \\
\text { Focus on process improvement }\end{array}$ \\
\hline
\end{tabular}

